Article

\title{
Selection of Optimal Operating Conditions for Extraction of Myrtus Communis L. Essential Oil by the Steam Distillation Method
}

\author{
Durmuş Alpaslan Kaya ${ }^{1}$, Mihaela Violeta Ghica ${ }^{2, *}$, Elena Dănilă ${ }^{3, *}$, Şevket Öztürk ${ }^{1}$, \\ Musa Türkmen ${ }^{1}{ }^{\circledR}$, Mădălina Georgiana Albu Kaya ${ }^{4}$ and Cristina-Elena Dinu-Pîrvu ${ }^{2}$ \\ 1 Department of Field Crops, Faculty of Agriculture, Mustafa Kemal University, 31034 Antakya-Hatay, Turkey; \\ dak1976@msn.com (D.A.K.); osevket@hotmail.com (S.Ö.); turkmenmusa@hotmail.com (M.T.) \\ 2 Department of Physical and Colloidal Chemistry, Faculty of Pharmacy, University of Medicine and \\ Pharmacy "Carol Davila”, 20956 Bucharest, Romania; ecristinaparvu@yahoo.com \\ 3 Faculty of Applied Chemistry and Materials Science, University Politehnica of Bucharest, \\ 011061 Bucharest, Romania \\ 4 Department of Collagen, Division Leather and Footwear Research Institute, National Research and \\ Development Institute for Textile and Leather, 031215 Bucharest, Romania; albu_mada@yahoo.com \\ * Correspondence: mihaela.ghica@umfcd.ro (M.V.G.); elena.danila23@yahoo.com (E.D.); \\ Tel.: +40-74-448-6250 (M.V.G.)
}

Academic Editor: Maurizio Mulas

Received: 10 May 2020; Accepted: 19 May 2020; Published: 21 May 2020

\begin{abstract}
Myrtus communis L. is one of the important aromatic and medicinal species from the Mediterranean area. It is used in various fields such as culinary, cosmetic, pharmaceutical, therapeutic, and industrial applications. Thus, a Box-Wilson experimental plan was used in this study to select the optimal operating conditions in order to obtain high volumes of essential oils. The factorial design method was applied to evaluate at an industrial scale the effect of major process variables on the essential oil extraction from Myrtus communis L. herbs by the steam distillation method. The input variables considered as significant operating conditions were: $X_{1}$-boiler occupancy rate (boilers were filled to $50 \%, 75 \%$, and $100 \%$ ), $X_{2}$-distillation duration (distillation was continued 60,75 , and $90 \mathrm{~min}$ ), and $X_{3}$-particle size (herbs were cut in sizes of 10, 20, and $30 \mathrm{~mm}$ via guillotine). The dependent variable selected, coded as $\mathrm{Y}$, was the essential oil volume obtained (mL). The steps of the classical statistical experimental design technique were complemented with the Taguchi method to improve the extraction efficacy of essential oil from Myrtus communis L., and the optimum parameter conditions were selected: boiler occupancy rate $100 \%$, distillation duration $75 \mathrm{~min}$, and particle size $20 \mathrm{~mm}$. Following the optimum parameters, the GC-MS assay revealed for the Myrtus communis L. essential oil two predominant components, $\alpha$-pinene $-33.14 \%$ and eucalyptol $-55.09 \%$.
\end{abstract}

Keywords: Myrtus communis L. essential oil; factorial design; Taguchi approach; GC-MS assay

\section{Introduction}

Myrtus communis L., known as Myrtle, is one of the important aromatic and medicinal species from the Mediterranean area [1]. It is used in various fields such as culinary, cosmetic, pharmaceutical, therapeutic, and industrial applications [2-4]. Different species of myrtle showed the presence of essential oils, phenolic acids, flavonoids (quercetin, catechin, myricetin), tannins, anthocyanin, pigments, and fatty acids [3,5,6]. Essential oils of Myrtus species consist mainly of monoterpene hydrocarbons, oxygenated monoterpenes, ethers, esters, sesquiterpene hydrocarbons, oxygenated sesquiterpenes, aliphatic hydrocarbons, alcohols, and phenols distributed in various ratios depending 
on the geographical area (temperature, soil quality, day length), harvesting time, and genotype of the species [7-10].

Myrtus communis is an ancient sacred plant which was used in ceremonies and as a symbol of youth and beauty. In ancient mythology, myrtle was sacred to Aphrodite and become the plant of love. The name derives from the Greek Myron meaning balm, chrism, ointment. It has been known to Persians, Greeks, and other civilized nations since ancient times and is native to South America, Australia, the north-western Himalayas, the Middle East, West Asia, North Africa, and the Zagros mountain range regions but was first introduced to the world by the British in 1597. Myrtus communis grows in Mediterranean countries along the coastline and inland hills in spruce and pine forests and near riversides and it is also known as Myrtle, Hambeles, Mersin, and Murt [11].

Myrtle is an evergreen tree that grows to a height of about 1-5 m, with small leaves ovate or lanceolate, $2-5 \mathrm{~cm}$ long, and white flowers. This species is a very aromatic plant because of the high essential oil content in its leaf, flower, and fruit glands; the leaves also contain tannins and flavonoids [12,13].

Antimicrobial (antibacterial, antifungal, and antiviral) and antioxidant proprieties of compounds produced by Myrtus communis L. have been reported in numerous studies. For example, 1,8-cineol and linalool have shown a good bactericidal effect against Gram positive and Gram negative bacteria (Listeria monocytogenes, Streptococcus pyogenes, Proteus vulgaris, and Escherichia coli) [14]. Another study showed that some myrtle single compounds such as limonene, 1,8-cineole, and $\alpha$-pinene have significant activity against Mycobacterium tuberculosis [1].

The myrtle essential oil proved to have anti-inflammatory, anticancer, antiviral, antimicrobial, antifungal, antioxidant, antidiabetic, antiulcer, and anthelmintic properties [15-19].

Taking into account these therapeutic properties of myrtle essential oil, one of the top subjects in the essential oil industry is to obtain both high extracted volumes and optimal conditions of extraction with reduction of experimental trials [20]. The recent studies showed the use of response surface methodology (RSM) as effective and powerful statistical method to optimize the essential oils extraction. For example, RSM was applied to determine at the laboratory scale the optimum extraction parameters to obtain high volumes of essential oil from Citrus latifolia by distilling peels [21], and high yields of essential oil from Cyperus rotundus Linn. rhizomes [22], Piper betle L. fresh and cured leaves [23], and Pistacia lentiscus ripe berries [24]. Moreover, Taguchi orthogonal array design was used to optimize the essential oil extraction yield from aerial parts of Dracocephalum kotschyi Boiss [25]. The essential oils extraction process from Cymbopogon martinii (Palmarosa) leaves was studied by the Taguchi method combined with grey relational analysis [26]. The same Taguchi experimental design was applied to extract biodiesel from Manilkara zapota L. seed oil [27].

Also, the statistical optimization techniques were applied to analyze and optimize the extraction at laboratory scale of essential oil from Myrtus communis L. leaves originating from different countries, using various techniques.

Zermane et al., found that the supercritical fluid extraction $\left(\mathrm{SCCO}_{2}\right)$ process used to obtain essential oils from the Algerian myrtle leaves resulted in the maximum yield of $4.89 \mathrm{wt} \%$ for a temperature of $313 \mathrm{~K}$, pressure of $30 \mathrm{Mpa}$, and the lowest mean particle diameter [28]. Perreira et al., showed that the optimum experimental conditions resulting in a high yield of essential oil from Portugal myrtle leaves, using the same supercritical $\mathrm{CO}_{2}$ extraction method, refers to a pressure of $22 \mathrm{MPa}$, temperature of $51{ }^{\circ} \mathrm{C}$, and $\mathrm{SCCO}_{2}$ flow rate of $0.1 \mathrm{~kg} / \mathrm{h}$ [29]. Haj Ammar et al., studied the influence of three technological parameters involved in the hydrodistillation process on essential oil yield extracted from Tunisian myrtle leaves, and found that the ratio of vegetal material weight/water weight and the condensation flow had the most significant effect while the ultrasound exposure time effect can be neglected [30]. In another study by Haj Ammar et al., a wider screening design was used to find the best conditions for a higher extraction yield also from Tunisia myrtle leaves. In this case, the results indicated that the yield is mostly influenced by processing time, condensation flow, and the mass ratio of plant material:water, while the granulometry had a less important effect [31]. Ghasemi et al., 
performed a more complex study, analyzing the results for the essential oil yield obtained from Iranian myrtle leaves by two extraction techniques: supercritical fluid extraction using different operating conditions and hydrodistillation methods, concluding that the first method led to the best results [32].

Thus, the aim of this study was to select the optimal operating conditions in order to obtain high volumes of essential oils using a Box-Wilson factorial design complemented with response surface analysis and the Taguchi approach. This optimization method was successfully applied by the authors in the field of drug delivery systems to get the best values for the physical-chemical and biopharmaceutical parameters, as well as the most stable, robust, and insensitive to the noise factor responses [33-36]. To the best of our knowledge, in this study we investigated for the first time at an industrial scale the effect of major process variables (boiler occupancy rate, distillation time, and size of particles) on the volume of essential oil extracted from Myrthus communis L. herbs by steam distillation.

\section{Results and Discussion}

\section{Design of Experiments and Optimization Technique}

A 3-factor, 3-level Box-Wilson experimental plan was applied to establish the best extraction conditions of essential oils from Myrtus communis L. herbs at an industrial scale.

While a full $3^{3}$ factorial design requires 27 experiments, the Box-Wilson experimental plan reduces the number of trials to 15 . The Box-Wilson factorial design is also a face centered composite design that includes eight factorial points corresponding to $2^{3}$ full factorial design, six axial points corresponding to the face centers of the cube portion of the design, and one replicate at the centre of the design [33].

The essential oil volumes (mL) obtained during the extraction process from Myrtus communis $\mathrm{L}$. herbs and the Box-Wilson experimental plan used to conduct the experiments are summarized in Table 1.

Table 1. Coded values and physical levels of the variables used in different experimental trials of the fractional matrix Box-Wilson and the corresponding observed and predictive responses.

\begin{tabular}{cccccc}
\hline & \multicolumn{2}{c}{ Input Variables Coded Level (Physical Level) } & \multicolumn{2}{c}{ Response } \\
\cline { 2 - 5 } Trials No. & \multirow{2}{*}{$\mathbf{X}_{\mathbf{2}} \mathbf{( \% )}$} & & \multicolumn{2}{c}{$\mathbf{Y}(\mathbf{m L})$} \\
\cline { 5 - 6 } & & $1(60)$ & $1(10)$ & 280 & 309 \\
\cline { 4 - 6 } & $1(50)$ & $1(60)$ & $1(10)$ & 730 & 675 \\
2 & $3(100)$ & $3(90)$ & $1(10)$ & 295 & 248 \\
3 & $1(50)$ & $3(90)$ & $1(10)$ & 760 & 796 \\
4 & $3(100)$ & $1(60)$ & $3(30)$ & 275 & 308 \\
5 & $1(50)$ & $1(60)$ & $3(30)$ & 745 & 674 \\
6 & $3(100)$ & $3(90)$ & $3(30)$ & 270 & 247 \\
7 & $1(50)$ & $3(90)$ & $3(30)$ & 740 & 795 \\
8 & $3(100)$ & $2(75)$ & $2(20)$ & 285 & 336 \\
9 & $1(50)$ & $2(75)$ & $2(20)$ & 750 & 793 \\
10 & $3(100)$ & $1(60)$ & $2(20)$ & 545 & 538 \\
11 & $2(75)$ & $3(90)$ & $2(20)$ & 590 & 568 \\
12 & $2(75)$ & $2(75)$ & $1(10)$ & 560 & 519 \\
13 & $2(75)$ & $2(75)$ & $3(30)$ & 540 & 518 \\
14 & $2(75)$ & $2(75)$ & $2(20)$ & 555 & 565 \\
15 & $2(75)$ & & & & \\
\hline
\end{tabular}

The experimental data from the Box-Wilson design were subjected to the optimization technique based on the experimental design and response surface methodology complemented with Taguchi approach elements [33-36]. In the first stage of the optimization process, a stepwise regression analysis 
with a backward elimination subroutine was applied to the experimental data for setting out the reduced quadratic polynomial equation for the response (Equation (1)).

$$
\mathrm{Y}=18.518 \mathrm{X}_{3}-0.0543 \mathrm{X}_{2}^{2}-0.464 \mathrm{X}_{3}^{2}+0.122 \mathrm{X}_{1} \mathrm{X}_{2}
$$

In Equation $(1)$ only the significant terms $(p<0.05)$ were considered and indicate the interaction and quadratic effects of the extraction process operating conditions on the essential oil volume (Table 1 ). The regressional coefficient values in the above equation explain their influence on the selected response. For a response that has to be maximized according to the constraint from Table 6, a positive sign means a synergistic effect while a negative sign means an antagonistic effect of the corresponding input variables. Thus, the coefficients of the reduced model in Equation (1) show that for $X_{3}$ a positive linear effect is noticed, while for both quadratic forms of $X_{2}$ and $X_{3}$ a negative effect appears. The essential oil volume is positively influenced by the interaction between $X_{1}$ and $X_{2}$.

The above reduced quadratic polynomial equation was assessed through the determination coefficient $\left(\mathrm{R}^{2}\right)$, correlation coefficient $(\mathrm{R})$, analysis of variance (ANOVA), and residual analysis, respectively. The $R^{2}$ value of 0.9948 was higher than 0.90 , while $R$ value was 0.9974 , closed to 1 . ANOVA results proved the statistical significance of the regressional model, the value for the model probability being smaller than $<0.0001$. The results of the residual analysis are listed in Table 1 . All these results indicated a good predictive power of the reduced regressional equation. The summary of variance analysis is presented in Table 2, indicating the statistical significance of the regression model.

Table 2. Analysis of variance for the reduced regressional polynomial model.

\begin{tabular}{ccccccc}
\hline Responses & Sources of Variation & Sum of Squares & df & Mean Squares & $\boldsymbol{F}$-Value & $\boldsymbol{p}$-Value \\
\hline \multirow{2}{*}{$\mathrm{Y}$} & Regression & 4704598 & 4 & 1176150 & & \\
& Residual & 24552 & 11 & 2232 & 526.94 & $<0.0001$ \\
& Total & 4729150 & 15 & & & \\
\hline
\end{tabular}

The observed and predicted values are well correlated as resulting from the residual analysis given in Table 1 and Figure 1a, in which a linear distribution is noticed.

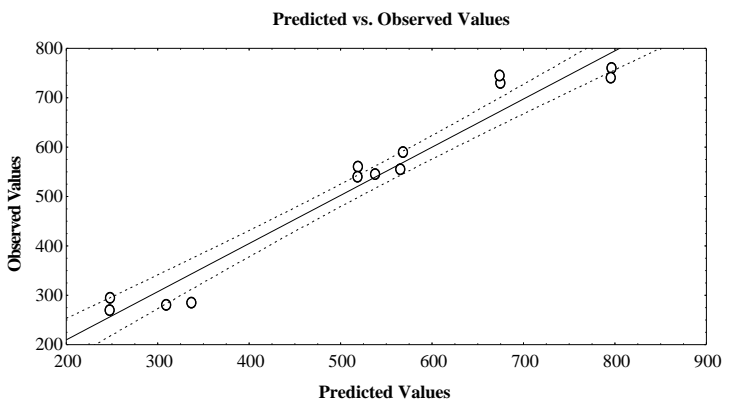

(a)

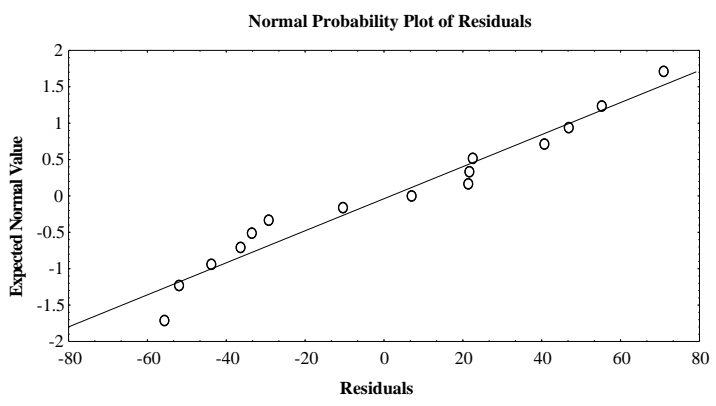

(b)

Figure 1. (a) Plot showing correlation between observed and predicted values for essential oil volume $(\mathrm{mL})$; (b) plot showing correlation between expected normal values and residuals for essential oil volume (mL).

Also, the difference between observed and predicted responses expressed as normal probability plots of residuals validated the design normality. The robustness of the design is confirmed by the distribution near a straight line of the response experimental values (Figure $1 \mathrm{~b}$ ).

The relationship between the dependent variables and two independent variables were further analyzed by response surface methodology. Three-dimensional (3D) response surface graphs were 
built (Figure 2a-c). The 3D graphs allow the visualization of the combined effects of the operating parameters on the essential oil volume obtained under different experimental conditions.

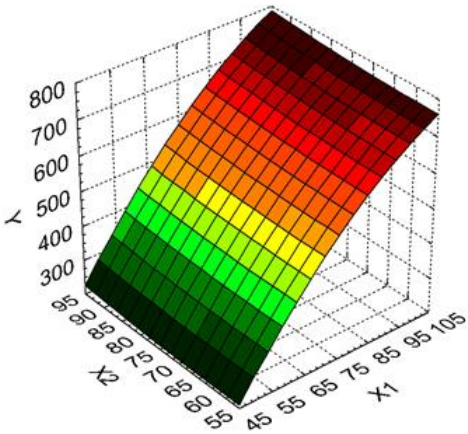

(a)

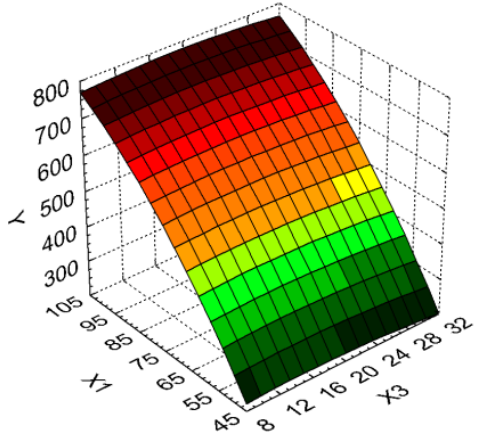

(b)

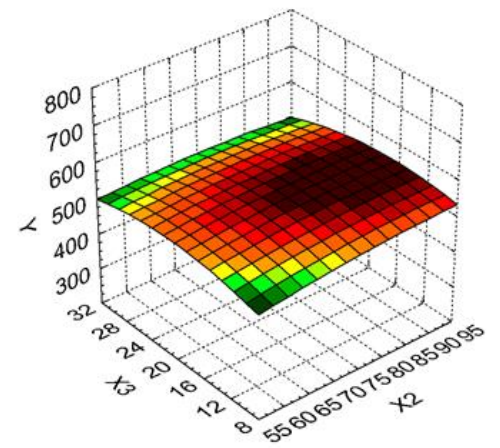

(c)

Figure 2. 3D response surface and contour plot showing the effect of different operating conditions on essential oil volume $(\mathrm{Y})$ : (a) boiler occupancy rate $\left(\mathrm{X}_{1}\right)$ and duration of distillation $\left(\mathrm{X}_{2}\right)$; $(\mathbf{b})$ boiler occupancy rate $\left(\mathrm{X}_{1}\right)$ and particle size $\left(\mathrm{X}_{3}\right)$; (c) duration of distillation $\left(\mathrm{X}_{2}\right)$ and particle size $\left(\mathrm{X}_{3}\right)$.

From Figure 2a,b it is determined that the best values for the essential oil volume are obtained for a higher boiler occupancy rate. Thus, an increase of $171.10 \%$ for the essential oil volume (from $275 \mathrm{~mL}$ to $745 \mathrm{~mL}$ ) was recorded when the boiler occupancy rate varied from minimum to maximum levels and the duration of distillation was kept at the minimum level. For the duration of the distillation increase from the minimum to the maximum level when the boiler occupancy rate was at the maximum level, the essential oil volume increased only $4.11 \%$ (from $730 \mathrm{~mL}$ to $760 \mathrm{~mL}$ ). A similar dependency was recorded for the influence of the boiler occupancy rate and the particle size on the essential oil volume (Figure 1b).

The essential oil volume as a function of the duration of distillation and particle size (Figure 2c) indicates that its highest values are obtained for middle particles sizes, and medium to high duration of distillation.

Taking into consideration all remarks above, we could conclude that the optimum variation levels for operating parameters in the extraction process of the essential oil from Myrtus communis L. herbs are as follows: $\mathrm{X}_{1}:[70 \div 100] \%, \mathrm{X}_{2}:[70 \div 90] \mathrm{min}, \mathrm{X}_{3}:[10 \div 20] \mathrm{mm}$. It seems that a higher boiler occupancy rate and duration of distillation conduct an increase of the essential oil volume, while the same effect is recorded for smaller particle size of the leaves.

The steps of the statistical experimental design technique previously detailed were complemented with the Taguchi method to improve the quality of the extraction process of essential oil from Myrtus communis L. herbs. The noise impact on the characteristic target was mathematically evaluated through the signal-to-noise ratio $(\mathrm{S} / \mathrm{N})$.

The signal-to-noise ratio for a criterion that has to be maximized coded as "larger-the-better" was computed (Table 3) for each experiment from Box-Wilson design, being specific to the dispersion 
around the value of the analyzed response for the combination of the tested operating parameters for the extraction process.

Table 3. The values for the signal/noise (S/N) ratio of the system response for the experiments included in the fractional factorial design.

\begin{tabular}{cccccccccccccccc}
\hline Run Order & $\mathbf{1}$ & $\mathbf{2}$ & $\mathbf{3}$ & $\mathbf{4}$ & $\mathbf{5}$ & $\mathbf{6}$ & $\mathbf{7}$ & $\mathbf{8}$ & $\mathbf{9}$ & $\mathbf{1 0}$ & $\mathbf{1 1}$ & $\mathbf{1 2}$ & $\mathbf{1 3}$ & $\mathbf{1 4}$ & $\mathbf{1 5}$ \\
\hline $\mathrm{S} / \mathrm{N}(\mathrm{dB})$ & 48.94 & 57.26 & 49.36 & 57.61 & 48.78 & 57.44 & 48.62 & 57.38 & 49.0 & 57.50 & 54.72 & 55.41 & 54.96 & 54.64 & 54.88 \\
\hline
\end{tabular}

The control factors (independent variables $X_{1}-X_{3}$ ) effects on the $S / N$ for the selected response (Y), resulting in the optimal combination of the extractive operational conditions, are given in Table 4 and Figure 3.

Table 4. Optimal combinations of independent variables coded levels, identified by the Taguchi technique, and their effect size on $\mathrm{S} / \mathrm{N}$ ratio for the dependent variable, expected, and observed $\mathrm{S} / \mathrm{N}$ value.

\begin{tabular}{ccc}
\hline \multirow{2}{*}{ Control Factors (Independent Variables) } & \multicolumn{2}{c}{ Y } \\
\cline { 2 - 3 } & “Larger—the-Better” & Effect Size \\
\hline $\mathrm{X}_{1}$ & 3 & 3.662 \\
$\mathrm{X}_{2}$ & 2 & 0.438 \\
$\mathrm{X}_{3}$ & 2 & 0.545 \\
\hline S/N expected $(\mathrm{dB})$ & 58.42 & \\
S/N observed (dB) & 57.50 & \\
\hline
\end{tabular}

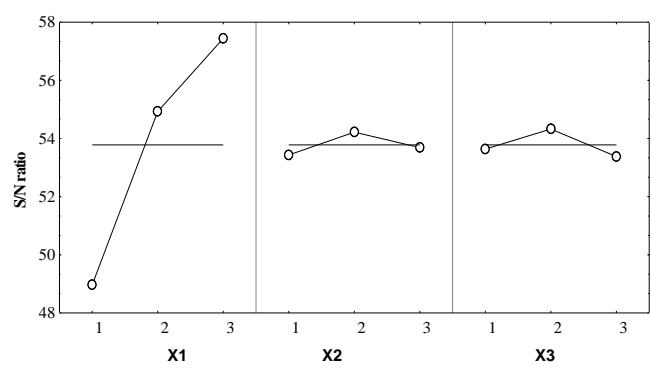

Figure 3. Control factors effects on the $\mathrm{S} / \mathrm{N}$ ratio for the essential oil volume.

From Figure 3 it can be noticed that $X_{1}$ parameter has the most significant influence on the $Y$ response. The optimal coded level of this formulation factor was 3 , meaning that this level involved a reduction of the noise factors effect.

For $X_{2}$ and $X_{3}$ a smaller influence on the response was remarked, in both cases the noise factors effect reduction was consequently obtained for the coded level 2.

The effect size (Table 4 ) of the operating conditions on the $\mathrm{S} / \mathrm{N}$ ratio gives the information concerning their influence degree on the system responses. Thus, the boiler occupancy rate was the main influencing factor for the essential oil volume, the effect size being 8.36 times higher than the duration of distillation and 6.72 times higher than the particle size.

Using the Taguchi technique, a combination of the operating parameters belonging to the initial fractional factorial design was selected (Run 10). The response obtained did not have the biggest value (see Table 1) but was the most robust, stable, and insensitive to the noise factors. For this experiment, close values are obtained for the $\mathrm{S} / \mathrm{N}$ ratio between the predictive value $(58.42 \mathrm{~dB})$ and the experimental one $(57.50 \mathrm{~dB})$.

The essential oil obtained in high volumes was characterized by GC-MS and the components were obtained as shown in Table 5 . 
Table 5. Essential oil components of Myrtus communis L. herbs.

\begin{tabular}{cccccc}
\hline RT & Compound Name & SI & RSI & CAS Number & $\%$ \\
\hline 12.99 & $\alpha$-Phellandrene & 931 & 970 & $1529-99-3$ & 0.24 \\
13.38 & $\alpha$-Pinene & 985 & 987 & $80-56-8$ & 33.14 \\
14.19 & cis-Ocimene & 681 & 786 & $6874-10-8$ & 0.06 \\
15.49 & $\Delta$-3-Carene & 976 & 976 & $13466-78-9$ & 0.43 \\
15.96 & $\beta$-Pinene & 674 & 810 & $127-91-3$ & 0.09 \\
16.82 & $\gamma$-Terpinene & 958 & 978 & $99-85-4$ & 0.29 \\
18.08 & Eucalyptol & 984 & 985 & $470-82-6$ & 55.09 \\
20.73 & $\alpha$-Terpineolene & 875 & 923 & $586-62-9$ & 0.17 \\
21.50 & Linalool & 978 & 980 & $78-70-6$ & 1.79 \\
24.44 & trans-Pinocarveol & 897 & 956 & $547-61-5$ & 0.13 \\
26.43 & $\alpha$-Terpineol & 782 & 936 & $10482-56-1$ & 0.06 \\
27.00 & Terpinen-4-ol & 907 & 966 & $562-74-3$ & 0.15 \\
28.00 & $\beta$-Fenchyl alcohol & 938 & 955 & $470-08-6$ & 3.20 \\
33.73 & trans-Pinocarvyl acetate & 781 & 931 & $1686-15-3$ & 0.12 \\
35.27 & $3(10)$-Caren-4-ol, acetoacetic acid ester & 862 & 862 & NA & 1.08 \\
36.50 & $\alpha$-Terpinenyl acetate & 958 & 988 & $80-26-2$ & 1.93 \\
38.47 & $\beta$-Elemene & 759 & 891 & $515-13-9$ & 0.04 \\
39.15 & Linalyl acetate & 747 & 876 & $115-95-7$ & 0.14 \\
40.14 & trans-Caryophyllene & 955 & 970 & $87-44-5$ & 0.19 \\
41.96 & $\alpha$-Humulene & 872 & 940 & $6753-98-6$ & 0.08 \\
48.07 & Caryophyllene oxide & 738 & 893 & $1139-30-6$ & 0.06 \\
\hline
\end{tabular}

The GC-MS assay revealed for this essential oil obtained at industrial scale two components in high amounts: $\alpha$-pinene-33.14\% and eucalyptol-55.09\%. Other compounds found in amounts of more than $1 \%$ were: $\beta$-fenchyl alcohol $(3.20 \%)$, $\alpha$-terpinenyl acetate $(1.93 \%)$, linalool $(1.79 \%)$ and $3(10)$-caren-4-ol, and acetoacetic acid ester (1.08\%). The remaining identified components amount was only $3.77 \%$.

In the chemical composition some differences compared to literature studies for essential oil extracted by different procedures at laboratory scale were noticed. Some examples of chemical composition of the myrtle essential oil from leaf belonging to different regions and described by many authors are given hereafter.

Ghannadi and Dezfuly identified the major constituents of $M$. communis leaf essential oil from Iran, extracted through hydrodistillation method, as: $\alpha$-pinene $(37.8 \%), 1,8$-cineole $(23.1 \%)$, limonene $(17.1 \%)$, and linalool (10.1\%) [37].

Walle et al., identified myrtenol, myrtenol acetate, limonene (23\%), linalool (20\%), $\alpha$-pinene $(14 \%)$, and 1,8-cineol (11\%) as the most important constituents of myrtle essential oil from Ethiopia, obtained also by the hydrodistillation method [38].

According to Senatore et al., and using the same classical extraction method, linalool (36.5\%) and linalyl acetate $(16.3 \%)$ were found as the most abundant component in the Turkish myrtle essential oil, with other compounds in representative amount being 1,8-cineole $(10.5 \%)$, geranyl acetate $(8.0 \%)$, $\alpha$-terpineol (7.9\%), and $\alpha$-pinene (7.8\%) [39].

The oil extracted by hydrodistillation from leaves of plants grown in various locations in Sardinia contained mostly $\alpha$-pinene (generally $30.0 \%$, but reaching in one case a maximum of $59.5 \%$ ), 1,8-cineole (ranging from 15.9 to $41.7 \%$ with an average of $28.8 \%$ ), and limonene (ranging from 5.2 to $29.8 \%$ with an average of $17.5 \%$ ) as the most abundant components [40].

Spanish oil obtained using the hydrodistillation technique was characterized by a high content of myrtenyl acetate (35.9\%), 1,8-cineole (29.89\%), and a low content of $\alpha$-pinene (8.2\%) and limonene $(7.58 \%)$ [41].

The oil from Greece, extracted by steam distillation, was found to be rich in linalyl acetate (31.4\%), limonene (21.8\%), $\alpha$-pinene (18\%), and geranyl acetate (6.5\%) [42]. 
According to Ghasemi et al., differences between the number and amount of compounds identified for Iranian essential oil extracted by hydrodistillation and supercritical carbon dioxide were recorded [32]. The selectivity of the extraction was obvious for the $\mathrm{SCCO}_{2}$ where three major components were predominant ( $\alpha$-pinene (29.9 to 38.6\%), limonene (13.5 to $18.1 \%$ ), and 1,8 cineole (23.3 to $29.1 \%)$ ) in comparison with the conventional method ( $\alpha$-pinene $(31.8 \%), 1,8$-cineole $(24.6 \%)$, limonene $(14.8 \%)$, and linalol $(8.3 \%))$.

Tunisian oil obtained by steam distillation showed major components like myrtenyl acetate (20.75\%), 1,8-cineol (16.55\%), $\alpha$-pinene (15.59\%), linalool (13.30\%), and limonene (8.94\%) [8].

This composition variations are generated by a series of factors, such as: pedo-climatic conditions, harvesting period, different subspecies, extraction method applied, and operating conditions.

\section{Materials and Methods}

\subsection{Materials}

The Myrthus communis L. herbs were harvested during the full bloom period, when the amount of active substance was most intense, being dried after in the shade at room temperature.

\subsection{Methods}

\subsubsection{Obtaining Essential Oils}

Essential oils were obtained by the steam distillation extraction method from Myrthus communis L. herbs using special equipment developed by Mahan Cosmetics in Hatay, Turkey, and varying the following parameters: boiler occupancy rate, distillation duration, and particle size.

The distillation equipment consisted of 4 units, 2 active and 2 passive. When the active units were distilled, passive units were ready for distillation by discharging, cleaning, and filling. When the duration of the distillation of the active units reached the end, they were replaced by passive units and thus 24/7 continuous distillation was possible. Each distillation unit was $3 \mathrm{~m}$ high and had $500 \mathrm{~L}$ of water capacity. Water used in distillation was free of lime and heavy metals. With the automation program used, the parameters such as pressure, temperature, and time, which are exposed to the oiled plant during the distillation, were recorded and could be traced backwards. Low temperature $\left(98^{\circ} \mathrm{C}\right)$ and water vapor pressure $(1 \mathrm{bar})$ were used to keep the quality and yield of volatile oil high. Furthermore, the water vapor $\left(101^{\circ} \mathrm{C}\right)$ was directed through the gap between the two walls to prevent the inner wall from being cooled, evaporated, and condensed repeatedly and consequently to prevent deterioration of essential oil quality.

\subsubsection{Design of Experiments and Optimization Techniques}

In order to establish the best extraction conditions of essential oils from Myrtus communis L. herbs by the steam distillation method, a Box-Wilson factorial design was used (Table 6).

A 3-factor, 3-level Box-Wilson experimental plan was applied to establish the best extraction conditions of essential oils from Myrtus communis L. herbs at an industrial scale.

The input variables considered as significant operating conditions were boiler occupancy rate, distillation duration, and particle size, coded as $X_{1}, X_{2}$, and $X_{3}$. The boiler occupancy rate was varied between $50 \%$ and 100\%, the distillation duration was continued between 60 and $90 \mathrm{~min}$, and the herbs were cut to particle sizes between 10 and $30 \mathrm{~mm}$ via guillotine. Each independent variable was evaluated at three different coded levels: low, middle, and high, coded as 1, 2, and 3, respectively, and their values (under the uncoded and coded form) are given in Table 6. The dependent variable as the system response selected in the Box-Wilson design was the essential oil volume obtained $(\mathrm{mL})$ coded as $\mathrm{Y}$, its constraint being listed in Table 6. 
Table 6. Process variables and experimental conditions in 3-factor, 3-level Box-Wilson experimental designs.

\begin{tabular}{ccccc}
\hline \multirow{2}{*}{ Input Variables } & \multirow{2}{*}{ Coded Symbol } & \multicolumn{3}{c}{ Coded and Uncoded Variation Levels } \\
\cline { 3 - 5 } & & Low (1) & Middle (2) & High (3) \\
\hline Boiler occupancy rate, (\%) & $\mathrm{X}_{1}$ & 50 & 75 & 100 \\
Duration of distillation, (min) & $\mathrm{X}_{2}$ & 60 & 75 & 90 \\
Particle size, $(\mathrm{mm})$ & $\mathrm{X}_{3}$ & 10 & 20 & 30 \\
\hline Response & Coded Symbol & \multicolumn{3}{c}{ Constraint } \\
\hline Essential oil volume $(\mathrm{mL})$ & $\mathrm{Y}$ & Maximize \\
\hline
\end{tabular}

The experiments were randomly performed. The following response function approximated by the second degree polynomial equation (Equation (2)) was used to correlate the dependent variable (Y) with input parameters $\left(\mathrm{X}_{1}-\mathrm{X}_{3}\right)$ :

$$
Y=\beta_{0}+\beta_{1} X_{1}+\beta_{2} X_{2}+\beta_{3} X_{3}+\beta_{11} X_{1}^{2}+\beta_{22} X_{2}^{2}+\beta_{33} X_{3}^{2}+\beta_{12} X_{1} X_{2}+\beta_{13} X_{1} X_{3}+\beta_{23} X_{2} X_{3}
$$

where $\beta_{0}$ is the model constant, $\beta_{1}-\beta_{3}$ the linear coefficients, $\beta_{11}-\beta_{33}$ the quadratic coefficients, and $\beta_{12}, \beta_{13}, \beta_{23}$ the cross-products coefficients. Statistica StatSoft Release software package was used for the determination of the coefficients of Equation (1) by regressional analysis of the experimental data. A stepwise regression analysis was conducted to build the second order polynomial equations for the response variable. The significant terms $(p<0.05)$ were selected for the final equation and the reduced quadratic polynomial model was obtained. The best fitting mathematical model was selected based on the determination coefficient, correlation coefficient, analysis of variance, and residual analysis. To investigate the combined effect of independent variables on the response, three-dimensional response surfaces were also drawn. The Taguchi signal/noise ratio was finally used for the evaluation of the design robustness.

Taguchi Technique

Taguchi's technique is one of the most known methods for a robust experimental design that ensures the optimization of the product and the conditions of the process to obtain it. The robustness represents the quality of being able to overpass the on-going modifications. The Taguchi technique is a tool for process improvement and not for absolute optimization. In the frame of Taguchi's approach, the independent variables $\left(X_{1}-X_{3}\right)$ are considered control factors, which need to be optimized for reaching a specified value and to eliminate the variation. Besides the control factors, the system responses can be affected by the noise factors, influenced by the process deployment conditions, which are defined as the unwanted variability determining the decrease of the optimization process quality. In order to find a robust solution, Taguchi developed more than 70 such signal-to-noise ratios $(\mathrm{S} / \mathrm{N})$, according to the particular type of the characteristics involved. Among these, three performance indicators are the most used, "lower-the-better", "larger-the-better", and "nominal-the-better". In this case, taking into account the constraints imposed on dependent variable Y we used "larger-the-better" criterion, known in literature also as "more-is-better" or "higher-is-better". This S/N ratio can be seen as a criterion that has to be minimized if the reversed measured data are taken into account, using the following equation (Equation (3)) [30,31]:

$$
\frac{\mathrm{S}}{\mathrm{N}}=-10 \log \left(\frac{1}{\mathrm{n}} \sum_{\mathrm{i}=1}^{\mathrm{n}} \frac{1}{\mathrm{Y}_{\mathrm{i}}^{2}}\right)
$$

\subsubsection{Gas Chromatography-Mass Spectrometry (GC-MS) Analysis}

Essential oils from myrtle plants were stored in amber vial bottles at $+4{ }^{\circ} \mathrm{C}$ until analysis by GC-MS (Thermo Fisher Scientific, Milan, Italy). A sample of $5 \mu \mathrm{L}$ of essential oil taken from the 
essential oils stored for GC-MS analysis with the help of a micro syringe was injected into 2 mL vials containing cyclohexane. Analysis of the essential oils obtained in high volume was carried out by using a Thermo Scientific DSQ model Gas Chromatograph equipped with MS, auto sampler, and TR-5MS (5\% phenyl polysilphenylenesiloxane, $0.325 \mathrm{~mm} \times 60 \mathrm{~m}$ i.d, film thickness $0.25 \mu \mathrm{m})$. The carrier gas was helium (99.9\%) at a flow rate of $1 \mathrm{~mL} / \mathrm{min}$; ionization energy was $70 \mathrm{eV}$. Mass range was $\mathrm{m} / \mathrm{z} 50-650$ amu. Data acquisition was in scan mode. MS transfer line temperature was $280{ }^{\circ} \mathrm{C}$, MS ionization source temperature was $200{ }^{\circ} \mathrm{C}$, the injection port temperature was $250{ }^{\circ} \mathrm{C}$. The samples were injected with a 250 split ratio. The injection volume was $1 \mu \mathrm{L}$. Oven temperature was programmed in the range of 50 to $220{ }^{\circ} \mathrm{C}$ at $3{ }^{\circ} \mathrm{C} / \mathrm{min}$. The structure of each compound was identified by comparison with their mass spectrum (Wiley9 library). The data were handled using the Xcalibur software program (version 2.1.0 SP1, Thermo Fisher Scientific, Milan, Italy).

\section{Conclusions}

In order to obtain high volumes of myrtle essential oils a Box-Wilson factorial design was applied to evaluate at an industrial scale the effect of major process variables on the essential oil extraction from Myrtus communis L. herbs by the steam distillation method. The steps of the classical statistical experimental design technique were complemented with the Taguchi method to improve the quality of the extraction process of essential oil from Myrtus communis L., and the optimum parameter conditions were selected as follows: boiler occupancy rate 100\%, distillation duration 75 min, and particle size $20 \mathrm{~mm}$. Following the optimum parameters, the GC-MS assay revealed for the Myrtus communis L. essential oil two predominant components, $\alpha$-pinene- $33.14 \%$ and eucalyptol $-55.09 \%$.

Author Contributions: Conceptualization, D.A.K., M.V.G., E.D., M.G.A.K. and C.-E.D.-P.; methodology, D.A.K., M.V.G., E.D., Ş.Ö. and M.T.; software, S..Ö., M.T. and M.V.G.; validation, D.A.K. and C.-E.D.-P.; formal analysis, M.V.G., Ş.Ö., M.T., M.G.A.K. and C.-E.D.-P.; investigation, M.V.G., D.E., Ş.Ö., M.T., M.G.A.K. and C.-E.D.-P.; data curation, D.A.K. and M.V.G.; writing-D.A.K., M.V.G. and E.D.; writing-review and editing, D.A.K., M.V.G, and E.D.; visualization, M.G.A.K.; supervision, C.-E.D.-P. All authors have read and agreed to the published version of the manuscript.

Funding: This work was performed through the International Industrial R\&D Projects Support Program by TUBITAK (1509/9150005) and ANCSI, project no. PN 191703 02/2019. This paper was financially supported by University of Medicine and Pharmacy "Carol Davila" through contract no. 23PFE/17.10.2018 funded by the Ministry of Research and Innovation within PNCDI III, Program 1-Development of the National RD System, Subprogram 1.2-Institutional Performance-RDI excellence funding projects.

Conflicts of Interest: The authors declare no conflict of interest. The funders had no role in the design of the study; in the collection, analyses, or interpretation of data; in the writing of the manuscript, or in the decision to publish the results.

\section{References}

1. Aleksic, V.; Knezevic, P. Antimicrobial and antioxidative activity of extracts and essential oils of Myrtus communis L. Microbiol. Res. 2014, 169, 240-254. [CrossRef] [PubMed]

2. Kafkas, E.; Güney, M.; Sadighazadi, S.; Yildirim, H.; Kefayati, S. Volatile Compounds of selected white and black Myrtle (Myrtus Communis L.) types from Mediterranean region of Turkey. J. Med. Plants Res. 2013, 7 , 1244-1248.

3. Wissam, Z.; Ali, A.; Walaa, I. Improvement of polyphenolic content and antioxidant activity of Syrian myrtle berries (Myrtus communis L.) hydro-alcoholic extracts using flavoring additives. Prog. Nutr. 2017, 19, 112-120.

4. Franco, A.M.; Tocci, N.; Guella, G.; Dell'Agli, M.; Sangiovanni, E.; Perenzoni, D.; Vrhovsek, U.; Mattivi, F. Myrtle Seeds (Myrtus communis L.) as a rich source of the bioactive ellagitannins oenothein B and eugeniflorin $\mathrm{D}_{2}$. ACS Omega 2019, 4, 15966-15974. [CrossRef]

5. Kanoun, K.; Belyagoubi-Benhammou, N.; Ghembaza, N.; Atik Bekkara, F. Comparative studies on antioxidant activities of extracts from the leaf, stem and berry of Myrtus communis L. Int. Food Res. J. 2014, 21, 1957-1962.

6. Bouzabata, A.; Cabral, C.; Gonçalves, M.J.; Cruz, M.T.; Bighelli, A.; Cavaleiro, C.; Casanova, J.; Tomi, F.; Salgueiro, L. Myrtus communis L. as source of a bioactive and safe essential oil. Food Chem. Toxicol. 2015, 75, 166-172. [CrossRef] 
7. Bouzabata, A.; Casanova, J.; Bighelli, A.; Cavaleiro, C.; Salgueiro, L.; Tomi, F. The genus Myrtus L. in Algeria: Composition and biological aspects of essential oils from M. communis and M. nivellei: A review. Chem. Biodivers. 2016, 13, 672-680. [CrossRef]

8. Ben Hsouna, A.; Hamdi, N.; Miladi, R.; Abdelkafi, S. Myrtus communis essential oil: Chemical composition and antimicrobial activities against food spoilage pathogens. Chem. Biodivers. 2014, 11, 571-580. [CrossRef]

9. Mulas, M.; Melis, R.A.M. Essential oil composition of Myrtle (Myrtus communis) leaves. J. Herbs Spices Med. Plants 2011, 17, 21-34. [CrossRef]

10. Aidi Wannes, W.; Mhamdi, B.; Marzouk, B. Essential oil composition of two Myrtus communis L. varieties grown in North Tunisia. Ital. J. Biochem. 2007, 56, 180-186.

11. Asif, H.M.; Akram, M.; Uddin, S.; Hasan, Z.; Sami, A.; Iqbal, A.; Tauseef, U.; Bari, A. Myrtus communis L. (Pharmacological activity). J. Med. Plants Res. 2011, 5, 6257-6259.

12. Nassar, M.I.; Aboutabl, E.S.A.; Ahmed, R.F.; El-Khrisy, E.D.A.; Ibrahim, K.M.; Sleem, A.A. Secondary metabolites and bioactivities of Myrtus communis. Pharmacognosy Res. 2010, 2, 325-329. [CrossRef] [PubMed]

13. Gençler Özkan, A.M.; Gençler Güray, C.A. Mediterranean: Myrtus communis L. (Myrtle). In Plants and Culture: Seeds of the Cultural Heritage of Europe; Morel, J.-P., Mercuri, A.M., Eds.; Edipuglia: Bari, Italy, 2009; pp. 159-168. ISBN1 8872285747. ISBN2 9788872285749.

14. Oyedemi, S.O.; Okoh, A.I.; Mabinya, L.V.; Pirochenva, G.; Afolayan, A.J. The proposed mechanism of bactericidal action of eugenol, $\alpha$-terpineol and g-terpinene against Listeria monocytogenes, Streptococcus pyogenes, Proteus vulgaris and Escherichia coli. Afr. J. Biotechnol. 2009, 8, 1280-1286.

15. Aleksic, V.; Mimica-Dukic, N.; Simin, N.; Nedeljkovic, N.S.; Knezevic, P. Synergistic effect of Myrtus communis L. essential oils and conventional antibiotics against multi-drug resistant Acinetobacter baumannii wound isolates. Phytomedicine 2014, 21, 1666-1674. [CrossRef]

16. Akdemir Evrendilek, G. Empirical prediction and validation of antibacterial inhibitory effects of various plant essential oils on common pathogenic bacteria. Int. J. Food Microbiol. 2015, 202, 35-41. [CrossRef]

17. Curiel, J.A.; Pinto, D.; Marzani, B.; Filannino, P.; Farris, G.A.; Gobbetti, M.; Rizzello, C.G. Lactic acid fermentation as a tool to enhance the antioxidant properties of Myrtus communis berries. Microb. Cell Fact. 2015, 14, 67. [CrossRef]

18. Kim, K.Y.; Jang, H.H.; Lee, S.-N.; Kim, Y.-S.; An, S. Effects of the myrtle essential oil on the acne skin-clinical trials for Korean women. Biomed. Dermatol. 2018, 2, 28. [CrossRef]

19. Hennia, A.; Nemmiche, S.; Dandlen, S.; Miguel, M.G. Myrtus communis essential oils: Insecticidal, antioxidant and antimicrobial activities: A review. J. Essent. Oil Res. 2019, 31, 487-545. [CrossRef]

20. Ansari, K.; Goodarznia, I. Optimization of supercritical carbon dioxide extraction of essential oil from spearmint (Mentha spicata L.) leaves by using Taguchi methodology. J. Supercrit. Fluid 2012, 67, 123-130. [CrossRef]

21. Tan, Q.L.P.; Kieu, X.N.T.; Kim, N.H.T.; Hong, X.N.T. Application of response surface methodology (RSM) in condition optimization for essential oil production from Citrus latifolia. Emir. J. Food Agric. 2012, 24, 25-30. [CrossRef]

22. Wang, H.; Liu, Y.; Wei, S.; Yan, Z. Application of response surface methodology to optimise supercritical carbon dioxide extraction of essential oil from Cyperus rotundus Linn. Food Chem. 2012, 32, 582-587. [CrossRef] [PubMed]

23. Madhumita, M.; Guha, P.; Nag, A. Extraction of betel leaves (Piper betle L.) essential oil and its bio-active identification: Process optimization, GC-MS analysis and anti-microbial activity. Ind. Crops Prod. 2019, 138, 111578. [CrossRef]

24. Belhachat, D.; Mekimene, L.; Belhachat, M.; Ferradji, A.; Aid, F. Application of response surface methodology to optimize the extraction of essential oil from ripe berries of Pistacia lentiscus using ultrasonic pretreatment. J. Appl. Res. Med. Aromat. Plants 2018, 9, 132-140. [CrossRef]

25. Nejad-Sadeghi, M.; Taji, S.; Goodarznia, I. Optimization of supercritical carbon dioxide extraction of essential oil from Dracocephalum kotschyi Boiss: An endangered medicinal plant in Iran. J. Chromatogr. A 2015, 1422, 73-81. [CrossRef] [PubMed]

26. Thakker, M.R.; Parikh, J.K.; Desai, M.A. Microwave assisted extraction of essential oil from the leaves of Palmarosa: Multi-response optimization and predictive modeling. Ind. Crops Prod. 2016, 86, 311-319. [CrossRef] 
27. Sathish Kumar, R.; Sureshkumar, K.; Velraj, R. Optimization of biodiesel production from Manilkara zapota (L.) seed oil using Taguchi method. Fuel 2015, 140, 90-96. [CrossRef]

28. Zermane, A.; Larkeche, O.; Meniai, A.-H.; Crampon, C.; Badens, E. Optimization of essential oil supercritical extraction from Algerian Myrtus communis L. leaves using response surface methodology. J. Supercrit. Fluid 2014, 85, 89-94. [CrossRef]

29. Pereira, P.; Bernardo-Gil, M.G.; João Cebola, M.; Mauricio, E.; Romano, A. Supercritical fluid extracts with antioxidant and antimicrobial activities from myrtle (Myrtus communis L.) leaves. Response surface optimization. J. Supercrit. Fluid. 2013, 83, 57-64. [CrossRef]

30. Haj Ammar, A.; Zagrouba, F.; Romdhane, M. Optimization of operating conditions of Tunisian myrtle (Myrtus communis L.) essential oil extraction by a hydrodistillation process using a $2^{4}$ complete factorial design. Flavour Fragr. J. 2010, 25, 503-507. [CrossRef]

31. Haj Ammar, A.; Zagrouba, F.; Romdhane, M.; Abderrabba, M. Extraction of myrtle (Myrtus communis L.) essential oil from Tunisia by hydrodistillation [Extraction de l'huile essentielle de myrte (Myrtus communis L.) provenant de la Tunisie par hydrodistillation]. Acta Hortic. 2010, 853, 241-250. [CrossRef]

32. Ghasemi, E.; Raofie, F.; Najafi, N.M. Application of response surface methodology and central composite design for the optimisation of supercritical fluid extraction of essential oils from Myrtus communis L. leaves. Food Chem. 2011, 126, 1449-1453. [CrossRef]

33. Ghica, M.V.; Albu, M.G.; Leca, M.; Popa, L.; Moisescu, S. Design and optimization of some collagen-minocycline based hydrogels potentially applicable for the treatment of cutaneous wounds infections. Pharmazie 2011, 66, 853-861. [PubMed]

34. Ghica, M.V.; Popa, L.; Saramet, G.; Leca, M.; Lupuliasa, D.; Moisescu, S. Optimization of the pharmaceutical products and process design applying Taguchi quality engineering principles. Farmacia 2011, 59, 321-328.

35. Ghica, M.V.; Albu, M.G.; Popa, L.; Moisescu, S. Response surface methodology and Taguchi approach to assess the combined effect of formulation factors on minocycline delivery from collagen sponges. Pharmazie 2013, 68, 340-348. [PubMed]

36. Ghica, M.V.; Albu Kaya, M.G.; Dinu-Pîrvu, C.-E.; Lupuleasa, D.; Udeanu, D.I. Development, optimization and in vitro/in vivo characterization of collagen-dextran spongious wound dressings loaded with flufenamic acid. Molecules 2017, 22, 1552. [CrossRef]

37. Ghannadi, A.; Dezfuly, N. Essential oil analysis of the leaves of Persian true myrtle. Int. J. Med. Arom. Plants 2011, 1, 48-50.

38. Walle, M.; Walle, B.; Zerihun, L.; Makonnen, E. Sedative-hypnotic like effect of the essential oil from the leaves of Myrtus communis on mice. Am. J. Biomed. Life Sci. 2014, 2, 70-77. [CrossRef]

39. Senatore, F.; Formisano, C.; Napolitano, F.; Rigano, D.; Özcan, M. Chemical composition and antibacterial activity of essential oil of Myrtus communis L. growing wild in Italy and Turkey. J. Essent. Oil Bear. Plants 2013, 9, 162-169. [CrossRef]

40. Tuberoso, C.I.; Barra, A.; Angioni, A.; Sarritzu, E.; Pirisi, F.M. Chemical composition of volatiles in Sardinian myrtle (Myrtus communis L.) alcoholic extracts and essential oils. J. Agric. Food. Chem. 2006, 54, 1420-1426. [CrossRef]

41. Boelens, M.H.; Jimènez, R. The chemical composition of Spanish myrtle oils. Part II. J. Essent. Oil Res. 1992, 4, 349-353. [CrossRef]

42. Koukos, P.K.; Papadopoulou, K.I.; Papagiannopoulos, A.D.; Patiaka, D.T. Chemicals from Greek forestry biomass: Constituents of the leaf oil of Myrtus communis grown in Greece. J. Essent. Oil Res. 2001, 13, $245-246$. [CrossRef]

Sample Availability: No samples of the compounds are available from the authors. 